\title{
LA INICIATIVA BUSH PARA LAS AMERICAS: ¿GESTO VACIO, HABIL ESTRATEGIA O CAMBIO RESEÑABLE EN LAS RELACIONES CONTINENTALES?
}

\author{
Josep S. Tulchin (*) \\ (Traducción de José Antonio de la Fuente Portugal)
}

El 27 de junio de 1990, embajadores y burocracia de altos puestos de todo Washington, fueron convocados en la Casa Blanca al mediodía para escuchar un importante discurso del presidente George Bush. El alcance y la urgencia del llamamiento eran poco comunes en Washington, y los diversos embajadores latinoamericanos que asistieron a la sesión, informaron que tenían la impresión de estar asistiendo a un momento trascendental en la historia. Reunidos en la East Room de la Casa Blanca, los embajadores, el gabinete, y los altos consejeros del gobierno escucharon un discurso en el que el presidente anunciaba formalmente la Iniciativa para las Américas.

El presidente comenzó refiriéndose a los dramáticos acontecimientos habidos en el mundo durante el año anterior, vinculando los cambios con la "creciente tendencia hacia la democracia antes nunca presenciada en la historia de este querido continente". Manifestó que "la profunda transformación política...tiene su paralelo en América Latina y el Caribe en la esfera económica". como resultado de la reunión de Cartagena (Colombia), celebrada en febrero de 1990 con los mandatarios andinos, el presidente ha comenzado una revisión de gran alcance de la política económica para con "esta región vital...Ese análisis está ahora completo", anadió, "y la necesidad de nuevas iniciativas económicas es clara y apremiante". Continuó, "Todos los indicios apuntan el hecho de que debemos modificar el foco de atención de nuestra influencia mutua económica hacia una nueva asociación de tipo económico dado que la prosperidad en nuestro continente depende del comercio, no de la ayuda. Hoy les he hecho aquí partícipes de algunas de las ideas y caminos por los que podemos construir una sociedad común fuertemente consolidada para los noventa, y anunciar que la nueva Iniciativa de las Américas crea incentivos para reforzar el reconocimiento de que América Latina está creciendo y que la reforma del libre mercado es la clave para sostener el crecimiento y la estabilidad política".

La nueva política poseería "tres pilares", comercio, inversión y deuda, e incluiría la acción necesaria para fortalecer las políticas medioambientales en este continente. Tras una referencia al próximo Quinto Centenario, declaró con un rasgo de retórico triunfalismo:
"Hoy, los vínculos de nuestra común herencia se hallan fortalecidos por el amor a la libertad y un común compromiso con la democracia. Nuestro desafío, el reto en esta nueva era para América es afianzar este sueño compartido y todos sus frutos para todo el pueblo de América del Norte, Central y del Sur.

El exhaustivo plan que acabo de perfilar es prueba concluyente de que Estados Unidos es firme en avanzar constantemente hacia una nueva sociedad común con nuestros vecinos latinoamericanos y caribeños. Estamos preparados para desempeñar un papel constructivo en este período crítico y hacer así del nuestro el primer continente completamente libre en toda la historia".

La reacción en América Latina al discurso del presidente fue inmediata y entusiasta. No pocos fueron los círculos oficiales que en Estados Unidos y América Latina declararon ver la Iniciativa para las Américas como el heraldo de una nueva etapa en las relaciones continentales. En Washington, los representantes de varios países anunciaron su intención de sentarse a negociar acuerdos de libre comercio con la mayor prontitud posible. Diversos centros de investigación iniciaron proyectos de estudio exhaustivos sobre la Iniciativa para las Américas y sus consecuencias para la región. Desde Argentina a México muchos investigadores comenzaron a elaborar documentos de trabajo comparando la Iniciativa para las Américas con la Alianza para el Progreso y la Política de Buena Vecindad.

La administración recalcó que la nueva política del presidente formaba parte de un fenómeno mundial, y también parte del gran movimiento hacia las economías de mercado y las políticas democráticas. Según Roger B. Porter, uno de los consejeros del presidente en materia económica, la política en sí misma fue parte de un "sueño para América Latina construido sobre la base de la asociación basada en los vínculos comunes compartidos: asociación entre América Latina y el Caribe por un lado, y Estados Unidos por otro; asociación entre los gobiernos del continente y su sector privado; y asociación entre los sectores privados de los países de la región" (1). Esta explicación oficial de la Iniciativa para las Américas reconocía que había escasos recursos gubernamentales comprometidos. De eso se trataba: la Iniciativa Bush para las Américas se hallaba asentada 
sobre los mercados, la eliminación de las barreras al comercio y a la libre empresa y la reducción del Estado. Porter dijo en un discurso en la Americas Society durante el otoño de 1990, que "el desafío para los gobiernos latinoamericanos bajo la Iniciativa Bush, es suprimir obstáculos para un eficiente funcionamiento de los mercados, y generar un clima apropiado para la empresa". Los estados no deberían inmiscuirse en la producción, pero deberían "aplicar regulaciones que salvaguardaran las inversiones extranjeras y facilitaran la entrada y salida de capital"(2).

Casi dos años más tarde, David R. Malpass, Vicesecretario para Asuntos Interamericanos del Departamento de Estado, en su declaración ante la Comisión de Comercio Internacional de Estados Unidos, volvió a plantear los temas anunciados por el presidente Bush,

"En primer lugar, que los cambios ahora en marcha están revolucionando las estructuras económicas y políticas de América Latina. Estoy convencido de que cuando esta década concluya, viviremos en un continente muy diferente y mucho mejor de lo que hemos visto en los ochenta.

En segundo lugar, que los cambios en América Latina ofrecen oportunidades sin precedentes para nosotros aquí en Estados Unidos para mejorar nuestras vidas. Una América Latina democrática y en crecimiento, es vital para el bienestar y la seguridad de Estados Unidos". Malpass señaló que las exportaciones crean puestos de trabajo y que los 60 billones de dólares en exportaciones hacia América Latina representaban aproximadamente un millón de empleos. Si el comercio de Estados Unidos con América Latina se incrementase hasta 100.000 millones de dólares al final de la década, significaría la creación de cerca de otro millón de puestos de trabajo. Incrementar el comercio sería la clave para mejorar las relaciones entre Estados Unidos y América Latina; ello conduciría a la cooperación en otras áreas tales como la droga y el terrorismo, y, acabó concluyendo que todo ello llevaría a "aunar esfuerzos para preservar e intensificar la cooperación política y medioambiental para mantener la paz a lo largo y ancho de todo el continente y del mundo. La transformación de América Latina en una comunidad de naciones democrática y orientada hacia el mercado, significa que compartimos aspiraciones y valores comunes. Nada aumenta más la seguridad de Estados Unidos que formar parte de una comunidad de naciones con compromisos compartidos hacia la paz, la democracia y la libertad económica".

Dos años después, es apropiado preguntarse por los logros alcanzados -con toda la conmoción generada a su alrededor- y si la Iniciativa para las Américas ha cumplido con su promesa desde la perspectiva de Estados Unidos y desde la correspondiente latinoamericana. El propósito de este ensayo es evaluar la Iniciativa Bush para las Américas desde la posición ventajosa de Estados Unidos: cómo encaja en la política de Estados Unidos hacia la región y globalmente; cómo encaja en el aparato político de la administración Bush; qué probabilidades tiene de cumplir su promesa; y, cómo articulará las relaciones de Estados Unidos con América Latina durante los próximos años.

Para empezar, debemos entender el contexto estratégico y político en el que la Iniciativa surgió. Durante cerca de una década, Estados Unidos ha sido el sujeto de estudio de numerosos análisis preocupados por la relativa decadencia del país respecto a las comunidades económicas emergentes de Europa y Japón. Hasta el más optimista de los análisis mostraba el convencimiento de que los días del dominio de la economía internacional por parte de Estados Unidos, habían terminado y que lo mejor que podría ser anticipado para los años venideros estaría constituído por una suerte de mundo tripolar en el cual la influencia económica podría dividirse de modo uniforme en un "oeste" que hace frente al "este" al que la Unión Soviética ha dejado a su suerte (3). Por entonces, y de forma sorprendente, la Unión Soviética se derrumbó. Mientras el proceso de reforma en la Unión Soviética había experimentado un fuerte acelerón hasta el punto de hacerse cada vez más obvio que lo que había sido denominado bloque del Este y el Imperio del Diablo, apenas era una caricatura de lo que había sido, sobrevino otra fuerte sacudida cuando el muro de Berlín fue derribado por una muchedumbre de expectantes celebrantes el 9 de noviembre de 1989, y los países del Este de Europa, uno tras otro, declararon su independencia de la Unión Soviética y la determinación de formar estados democráticos vinculados al resto de Europa. De la noche a la mañana, la Unión Soviética se transformó -implosionó fue la palabra más utilizada entre los periodistas- en una confederación poco firme de estados peligrosamente cercanos a la impotencia. Ahora, en lugar de preocuparse por la destrucción mutua y la amenaza de un ataque militar procedente de un enemigo poderoso, los aliados occidentales pasaron a inquietarse por coordinar sus esfuerzos en proveer la ayuda económica juzgada como necesaria para mantener la antigua Unión Soviética del peligroso deslizamiento hacia el caos.

Los mandatarios de Occidente fueron poco claros a la hora de reaccionar ante los acontecimientos del Este. Algunos quisieron declarar la victoria de la guerra fría y un analista escribió acerca del "fin de la historia". En Estados Unidos, algunos miembros del Congreso vinieron a recoger los "dividendos de la paz" que serían utilizados para detener la decadencia de la economía de Estados Unidos y restablecer su competitividad, mientras que un estilo más generoso de trato para con los sin hogar, los pobres, y otros dilemas gravitan acechantes sobre el tejido social del país. El presidente Bush, optimista por naturaleza, percibió una tendencia global hacia la economía de mercado y la política democrática. Se hallaba particularmente estimulado por el movimiento liberador del comercio internacional. Creía profundamente en la eficacia del libre intercambio internacional sin trabas.

(2) ibid, p.6.

(3) La exposición clásica de lo que ha venido en ser denominado "imperial overreach" es la de Paul Kennedy, The Rise and Fall of the Great Powers (NY: Random House, 1987). Otros ejemplos con argumentos similares son: David P. Calleo, Beyond American Hegemony NY: Basic Books, 1987); Josef Joffe, The Limited Partnership (Cambridge, MA: Ballinger, 1987); and Joel Krieger, Reagan, Thatcher and the Politics of Decline (NY: Oxford University Press, 1987). Para una opinión muy diferente, ver Henry R. Nau, The Myth of America's Decline (NY: Oxford University Press, 1990). 
Este fue el reconocimiento del gobierno sobre lo que había venido a ser denominado el "Consenso de Washington" concerniente a la transformación del mercado internacional. De esta forma se reflejaba un punto de vista durante mucho tiempo sostenido por las agencias de préstamo internacionales y el Fondo Monetario Internacional, que representaba una visión ortodoxa de las virtudes y excelencias del libre mercado y la necesidad de reestructurar la marcha de las economías del antiguo bloque socialista y las economías proteccionistas del Tercer Mundo a través de líneas compatibles con las políticas de los países industrializados del Occidente desarrollado (4). Según esta perspectiva, con el fin de la guerra fría se experimentó una tendencia creciente hacia la apertura de la economía internacional, basada en la expansión del libre mercado y una mayor facilidad en el movimiento de capitales, trabajo e información a lo largo de las fronteras nacionales, para el beneficio de la comunidad internacional. Semejante reestructuración o reforma llevada a cabo por los países desarrollados, permitiría su reinserción en la cada vez más competitiva economía mundial, donde la eficiencia y las ventajas comparativas parecen ser las claves del éxito.

El final de la guerra fría liberó a las naciones del Este europeo, para, de esta forma, tomar parte en un movimiento ya en estado muy avanzado en el Hemisferio Occidental, donde, con la excepción de Cuba, todos los países son regidos por gobiernos elegidos democráticamente, una situación única en la historia de la región. Además, presionados y compelidos por la banca internacional y las demandas del Departamento del Tesoro de Estados Unidos, muchos de los gobiernos han dispuesto reformas económicas de profunda relevancia, dejando de lado los modelos de desarrollo basados en la sustitución de importaciones que habían dominado el ejercicio de la política prácticamente desde la Gran Depresión y habían constituído artículo de fe desde los años cincuenta, para cerrar sus economías al mercado internacional. El Consenso de Washington parecía así, global en su extensión y alcance.

Con todo, aunque estas tendencias eran enormemente estimulantes para el presidente Bush, este llegó a sentirse preocupado por la queja de los presidentes de los países andinos con quienes se había reunido a comienzos de 1990 para estudiar el engorroso problema del tráfico de drogas. El final de la guerra fría había apuntado un desplazamiento en los intereses de Estados Unidos hacia América Latina desde las cuestiones de seguridad hacia el libre comercio, la democracia, las drogas, las migraciones y el medio ambiente continentales, y el presidente Bush había ido a la reunión de Cartagena con la esperanza de una cooperación entusiasta por parte de sus colegas latinoamericanos. En lugar de ello, los mandatarios de Bolivia, Perú y Colombia le informaron que sus países -y el resto de la región- se hallaban atrapados en un momento de recesión económica. Informaron que los años ochenta habían constituído una década perdida para América Latina. La región había retrocedido en términos económicos, como consecuencia de la pesada carga de la enorme deuda externa impagada, cuyo resultado fue la paralización del caudal de capital privado, de modo que acabó arrastrando a la mayoría del continente a una recesión que fue socavando las nuevas y frágiles democracias. En presencia de la severa recesión, los gobiernos civiles fueron incapaces de aumentar los ingresos para satisfacer las necesidades legítimas de sus pueblos.

Para agravar el problema, los programas de reestructuración que sobre ellos fueron impuestos por los bancos internacionales como condición para renovar los préstamos, y, en algunos casos, por el Tesoro de Estados Unidos para la concesión de créditos por parte del Banco de Exportación-Importación u otras agencias federales, fueron socavando la fuerza del estado precisamente en un momento en que se precisaba un estado fuerte para consolidar las nuevas democracias y responder a las legítimas necesidades sociales, tales como el asombroso desempleo y otras como el tráfico de drogas, la degradación medioambiental, o el terrorismo, que estuvieron en la primera página de la agenda de Estados Unidos para el continente.

Pero el presidente Bush no se sintió atraído hacia un programa de ayuda oficial. Iba contra su propia filosofía y sabía que aún cuando adoptara un programa semejante, le llevaría arduos esfuerzos en venderlo al congreso y al pueblo americano que recelaba de la prolongada recesión, de los costos económicos y los escándalos de los préstamos que soportaban sobre sus hombros. Históricamente, con la excepción de la Alianza para el Progreso, Estados Unidos había respondido a las peticiones latinoamericanas de ayuda económica, instándoles a abrir sus mercados y permitir al capital norteamericano resolver sus problemas. "Comercio, no ayuda", fue la respuesta de los círculos oficiales de Estados Unidos a sus colegas latinoamericanos que demandaban para el continente un programa semejante al Plan Marshall puesto en práctica después de la Segunda Guerra Mundial. Bush no era el primer presidente de Estados Unidos en creer en los mágicos poderes curativos del mercado internacional.

Estas preocupaciones de índole general fueron orientadas por el presidente y sus consejeros al caso específico de México, donde el actual presidente, Carlos Salinas de Gortari, educado en Harvard, se había embarcado en un audaz programa de reformas diseñado con la intención de abrir la economía mexicana, cuyo inicio se llevó a cabo aumentando las inyecciones de capital extranjero y las privatizaciones. México había constituído un caso especial en América Latina para Estados Unidos durante muchos años. Aparte de los lazos obvios creados por una historia compartida, una frontera de 2.000 millas, y un alto nivel de interdependencia económica, los dos países se vieron forzados a hacer frente de forma conjunta a la migración más significativa -legal e ilegal- en el continente. El presidente Bush y el secretario de estado James Baker, como tejanos, tenían un conocimiento de México mucho mayor y exhaustivo que la mayoría de los norteamericanos, y un acusado sentido de que debían hacer algo por y para México. Como

(4) John Williamson, "What Washington Means by Policy Reform", en Williamson, (ed)., Latin American Adjustement: How Much Has Happened? (Washington, D.C. Institute for International Economics, 1990). 
tejanos, también tendieron a confundir el resto de América Latina con México. Lo que era bueno para México, indudablemente sería bueno para el resto de América Latina.

Reunidos en el rancho del Presidente en el sur de Texas, tuvieron en cuenta su reciente decisión de iniciar las conversaciones con México acerca de una zona de libre comercio, a la que se añadiría Canadá, constituyéndose así un área de libre comercio norteamericano. Atendieron también el próximo viaje del presidente a Suramérica en septiembre (5). Lo que allí surgió -el resultado de la planificación política pensada desde el interior mismo del Departamento del Tesoro por un pequeño grupo consultado a instancias del secretario Nicholas Brady- parecía el acuerdo perfecto. Fue diseñado para hacer frente a las principales preocupaciones de los países de la región, deuda, comercio y bienestar económico. Fue dirigido para el caso de México pero incluiría también el resto del continente. El plan estaba de acuerdo con la política de la administración en las negociaciones de la Ronda Uruguay del GATT, y venía a fortalecer el compromiso de los países latinoamericanos hacia la reforma multilateral del comercio, punto central en aquellas discusiones. Finalmente, a fuerza de insistir en el espíritu de familia continental, fue diseñado de forma que se acallaran las inquietudes profundamente arraigadas en los latinoamericanos sobre los residuales instintos de Estados Unidos hacia un comportamiento hegemónico en el continente.

El final de la guerra fría dejó en muchos mandatarios latinoamericanos una profunda inquietud. Se hallaban preocupados por el hecho de que Estados Unidos podría prestar incluso menos atención a la región ahora que su importancia estratégica era cuestionada. Por otro lado, la invasión de Panamá provocó nerviosismo en muchos latinoamericanos que, con el final de la guerra fría, vieron a un Estados Unidos que usaría su poder de una forma unilateral sin prestar la atención adecuada a los intereses latinoamericanos. Cabía esperar que la Iniciativa para las Américas calmara esos temores y creara un espíritu de buena voluntad hacia Estados Unidos, mientras complementariamente apoyaría los esfuerzos de éste último hacia el libre comercio mundial para así reforzar los esfuerzos y fortalecer los vínculos con México.

El problema de hacer descender la Iniciativa de las Américas al plano de la realidad, estribaba en que tenía escaso contenido específico y ninguna directriz para hacer efectiva la política general. La verdad simple y llana del asunto es que el anuncio en junio halló desprevenida a la burocracia norteamericana. Las conversaciones con México habían estado en las mesas de trabajo durante meses, pero esto era diferente. Debido a que la política había sido delineada en el Departamento del Tesoro, los de Comercio y Estado no tenían conocimiento exhaustivo del proceso al no estar en él involucrados. Al Departamento de Comercio le llevó una semana establecer una oficina con el objeto de tratar con la Iniciativa para las Américas, y el director de dicha oficina admitió no mucho más tarde no tener la más remota idea de lo que se suponía debía hacer, además de no disponer de personal. Seis meses antes el Departamento de Comercio habría estado en posición de haber desarrollado la nueva política de forma más efectiva. Por entonces, la Oficina del Representante de Comercio de Estados Unidos afirmó su derecho de iniciativa en la política, desde el punto y hora en que se basaba en el comercio, aunque en esto, tal como ocurría en el Departamento de Comercio, la primera nota desafinada fue la de la falta de previsión de la burocracia. Uno de los responsables oficiales más antiguos para América Latina dijo en una audiencia pública en Washington a finales de 1990, que el representante de comercio simplemente carecía de personal para negociar todos los tratados de libre comercio contemplados en la Iniciativa para las Américas y solamente podría ocuparse de los agrupamientos subregionales, aún cuando los citados fueran contrarios a la política del Depártamento del Tesoro en las negociaciones de la deuda (6).

El Departamento de Estado fue el más lento en responder, quizás porque había varias divisiones que creían tener el derecho a participar. A comienzos del nuevo año, la actividad concerniente a la Iniciativa para las Américas se centró en la oficina del Vicesecretario para Asuntos Latinoamericanos, actuando como enlace con la Agencia Internacional de Desarrollo. Y, como una pequeña parte de la Iniciativa tenía que ver con la deuda, el Departamento del Tesoro comenzó a ceder el territorio en el que se había aventurado durante el proceso de formulación política. Es más, durante cerca de un año después del discurso presidencial, la Iniciativa de las Américas era una política sin hogar y sin mando alguno coherente. Durante ese tiempo, no se le prestó prácticamente ninguna atención en la prensa y el Congreso manifestó poco interés con cualquier cosa que no fuera la autorización del "fast track" para las negociaciones con México. Nadie en el Capitolio podía apasionarse con la Iniciativa hasta que el caso mexicano hubiera sido resuelto, y el ciudadano a lo largo y ancho del país tenía dificultad para distinguir la Iniciativa de las Américas del Acuerdo de Libre Comercio (NAFTA). Cuando, por ejemplo, en el aniversario del anuncio original de la Iniciativa, el Presidente llamó al gabinete y al cuerpo diplomático al Jardín de Rosas de la Casa Blanca para ensalzar los éxitos de la propuesta durante el año anterior, en la conferencia de prensa que siguió a continuación, ni una sola pregunta fue realizada sobre la Iniciativa para las Américas; todo lo preguntado hacía referencia a asuntos de política doméstica.

Dar a la Iniciativa su contenido específico no ha sido nada fácil, dado que muchas de las iniciativas provienen de América Latina. El "pilar" del comercio como es llamado, se apoya sobre una compleja serie de compromisos genera-

\footnotetext{
(5) Con posterioridad el viaje fue retrasado hasta diciembre de 1990.

(6) Don Abelsen hizo algunas observaciones durante el coloquio de Sidney Weintraub en el Woodrow Wilson International Center for Scholars en diciembre de 1990, publicado posteriormente como parte del Papel de trabajo 195. El profesor Weintraub incorporó las observaciones de Abelson a su propio argumento para explicar el creciente regionalismo en la política comercial de Estados Unidos en su papel de trabajo, "The New US Economic Initiative Toward Latin America", Journal of Interamerican Studies, vol., (1991), pp. 1-18. La falta de personal fue una constante preocupación del Representante de Comercio de Estados Unidos, por ejemplo, ver la entrevista con Carla Hills, New York Times,2 de mayo de 1992,II,2
} 
les para liberar el comercio, conocidos como acuerdos marco, que han sido firmados prácticamente con todos los países del continente, significándose como un claro compromiso para crear un área de libre comercio "desde Alaska a Tierra del Fuego". A mediados de 1992 solamente Cuba, Surinam y Haití permanecían sin firmar los acuerdos marco con Estados Unidos. Para facilitar la negociación de los acuerdos comerciales con los países de la región, el aparato administrativo reclamó y ganó la autorización del "fast track" mediante la cual el Congreso se compromete por su parte a aceptar o rechazar únicamente en su totalidad un acuerdo comercial a él presentado, rechazando la aprobación de algunas provisiones y otras no. Además, debe votar la legislación a desarrollar dentro de un período de tiempo fijo. El 24 de mayo de 1991, el Congreso aprobó una extensión de dos años del "fast track" hasta el 1 de junio de 1993. Mientras el "fast track" puede beneficiar a la Iniciativa para las Américas, al mismo tiempo era deseado concluir el tratado mexicano de una forma más llevadera, dado que las tensiones políticas a éste asociadas amenazan con malograr el "fast track" para el resto de América Latina. (7)

El pilar de la deuda es el más débil de los tres. Trata exclusivamente la deuda oficial bilateral, que asciende a sólo 12.500 millones de dólares para toda la región de una deuda externa total superior a 400.000 millones de dólares. Desde luego, hay algunos paises, todos en la cuenca del Caribe, para los cuales la cantidad representa una porción considerable de su deuda externa total, pero es trivial e insignificante para los mayores deudores de la región, Argentina, Brasil y México, cuya deuda oficial asciende a 524 millones de dólares, 2.500 millones y 1.600 millones respectivamente. El perdón de la deuda debe ser aprobado por el Congreso y el ejecutivo ha comenzado el proceso solicitando modestas autorizaciones del Congreso en cada uno de los años físcales de 1992 y 1993.

El pilar de la inversión fue el menos definido en el documento original y permanece poco claro hasta el día de hoy. Después de un período de duda e indecisión, la administración Bush traspasó la parte de inversión de la Iniciativa al Banco Interamericano de Desarrollo en forma de un Fondo de Inversión Multilateral, que alcanzó 1.500 millones de dólares con importantes contribuciones procedentes de Japón, Alemania y otros países acreedores. Por añadidura, una pequeña cantidad fue puesta aparte, de nuevo a través del BID, para apoyar las reformas en el sector de inversiones.

Por otro lado, el comercio parece haber sido una idea impuesta por el devenir de los tiempos. Casi sin ser requerido, los países latinoamericanos comenzaron a reducir sus barreras arancelarias o a acelerar los procesos de reforma del comercio comenzados antes de junio de 1990. El ministro Sergio Amaral, como representante del gobierno brasileño, manifestó en la audición supervisada por la Comisión de Comercio Internacional de Estados Unidos en enero de 1992,

"Si hubiera sido invitado por la Comisión de Comercio
Internacional hace tres años a comparecer ante ella, me hubiera sentido incómodo explicando y justificando:

- La existencia de una lista de 1300 productos cuya importación estaba suspendida.

- Elevadas tasas arancelarias que, cuando son combinadas con impuestos adicionales pueden alcanzar un $300 \%$.

- La invocación del artículo XVIII b del GATT, durante casi dos décadas, para lograr una serie de impresionantes restricciones a la importación, a pesar del hecho de que los desequilibrios de la Balanza de Pagos eran reales.

Hoy, sin embargo, estoy agradecido por esta oportunidad que se me brinda de ponerles al día respecto al programa de liberalización de largo alcance que ha sido puesto en marcha en Brasil en los dos últimos años e informarles que, según la información de que dispongo, han desaparecido las barreras de acceso de los productos norteamericanos al mercado brasileño, excepto algunas restricciones en el área informática, que serán eliminadas hacia octubre de 1992. Un gran cambio ha tenido lugar en las políticas comerciales de Brasil, el cual ha tenido un impacto inmediato en las relaciones comerciales entre Estados Unidos y Brasil".

A continuación, el ministro Amaral se quejó de que Estados Unidos se estaba retrasando en la liberalización de su política comercial respecto a Brasil y otros países latinoamericanos, y urgió a Estados Unidos a adoptar una postura más agresiva en colaboración con los países del continente, haciendo frente así a las tendencias proteccionistas de algunos países europeos del GATT. La frustración con el GATT fue expresada también por el representante de Argentina en Ginebra, el embajador Archibaldo Lanús, que se quejó de que solamente América Latina estaba siguiendo las recomendaciones de los países desarrollados para suprimir las barreras al comercio, hecho que podía situar a estos países en un futuro cercano ante un mercado mundial en el que solamente los exportadores de materias primas hubieran bajado o eliminado las barreras comerciales, mientras los países desarrollados y sus mercados lógicos hubieran dejado sus barreras comerciales tan altas como ya las tenían con anterioridad (8).

La conexión entre el GATT, la Iniciativa de las Américas y el Tratado de Libre Comercio (NAFTA) es crucial para entender el acercamiento de Estados Unidos a la Iniciativa y el destino político de ésta en Washington. La dirección del Congreso veía la autorización del "fast track" para México como parte del esfuerzo del país para conseguir algo provechoso en las conversaciones de la Ronda Uruguay del GATT y no como parte de la Iniciativa de las Américas. La dirección de ambas cámaras aparece clara en una carta del senador Lloyd Bensten y del congresista Dan Rostenkowski dirigida al presidente el 7 de marzo de 1991, en la que señalaban sus inquietudes hacia los temas no resueltos del medio ambiente y el gran diferencial de estatus laborales entre los dos países. 
La respuesta del Presidente el 1 de mayo puso de relieve su compromiso con las negociaciones del libre comercio y acentuó la buena disposición del presidente Salinas hacia unos patrones medioambientales homologados. Al mismo tiempo, reiteró su deseo de trabajar estrechamente con el Congreso en los meses siguientes. El embajador Julius Katz, diputado representante de comercio de Estados Unidos dijo ante el Comité de finanzas del Senado que era intención de la administración consultar al Congreso cada paso de las negociaciones con México, de modo que el "fast track" no significaba la eliminación del Congreso del proceso del tratado. Y estaba en el interés de la administración no llegar a un nivel de relación hostil con aquel durante las negociaciones (9).

Fruto de la postura de cooperación del ejecutivo, durante los meses de verano el Congreso incluyó en la legislación anual sobre gastos, el consentimiento para una reducción modesta de la deuda, promesa incluída en la Iniciativa. El gobierno se movió rápidamente para firmar acuerdos bilaterales con Chile, Bolivia y Jamaica con el objeto de reducir la deuda de aquellos países sujetos a la Ley Pública 480 (PL 480), el Programa Alimentos para la Paz. Estos éxitos fueron contrarrestados por las dificultades económicas sufridas a comienzos del nuevo año fiscal, desde septiembre hasta diciembre, cuando el Congreso no pudo aprobar un presupuesto y dejó que el gobierno fuera financiado por resoluciones continuadas que mantuvieron el gasto en los niveles del presupuesto de 1991, hecho que significaba que la Iniciativa para las Américas perdía su liquidez por falta de recursos monetarios. Una vez que el presupuesto fue aprobado, el programa de perdón de la deuda pudo comenzar a ser desarrollado.

El fondo de inversión multilateral sufrió una vez más suerte adversa. El Congreso retrasó el acto de compromiso de Estados Unidos para contribuir con 100 millones de dólares, mientras los europeos manifestaron públicamente que ellos no pondrían su parte, a menos que Estados Unidos fuera a incrementar su compromiso a la reconstrucción de la antigua Unión Soviética y Europa del Este. Japón, después de alguna vacilación, acordó equiparar su contribución a la de Estados Unidos cuando ésta fuera hecha efectiva. Hacia mediados del verano de 1991 nada había salido aún del Congreso. El Banco Interamericano de Desarrollo se encontraba organizando el desembolso de fondos pero no había recibido nada que desembolsar. Si bien el fondo de inversión multilateral estuvo completado en los niveles deseados, el total se muestra insignificante -2.500 per capita- comparado a los esfuerzos realizados por los alemanes con el objeto de incorporar a sus hermanos de la antigua República Democrática -3.000 dólares per capita- o los gigantescos esfuerzos montados para reflotar las economías del Este de Europa y de la antigua Unión Soviética. Pero las insignificantes sumas en cuestión están justificadas por la administración Bush con el argumento de que son compro- misos simbólicos para echar a andar e involucrar al sector privado y estimular la iniciativa empresarial.

El sector privado norteamericano hizo oir lentamente su voz, a través de conferencias y audiciones llevadas a cabo a lo largo del país por el Representante de Comercio de Estados Unidos. Importantes y modestas empresas mostraron su apoyo al Tratado de Libre Comercio por la clarividencia del presidente al concebir una zona de libre comercio a lo largo y ancho del continente. El punto central de consenso fue articulado por la idea de que había mucho dinero que ganar en el continente para los negocios norteamericanos y los puestos de trabajo que serían creados, cientos de miles de empleos, como resultado directo del tratado. La única advertencia vino de los empresarios de la industria ligera y textil que insistieron en que a menos que los tratados con los países de bajo nivel salarial en el continente incluyeran provisiones específicas para la suma de inversiones locales, las exportaciones asiáticas les utilizarían simplemente como plataformas de reexportación e inundarían el mercado norteamericano con mercancías y artículos baratos (10).

La única objeción pública a la Iniciativa para las Américas en estas primeras audiciones,vino del mundo laboral y de aquellos que proclamaban hablar en nombre del mundo del trabajo. En una presentación formal al Representante de Comercio en Boston, Massachussets, cuatro economistas guiados por Samuel Bowles, de la Universidad de Massachussets, afirmaron que el Tratado de Libre Comercio conduciría a un incremento dramático de la inversión privada directa de Estados Unidos en México, hecho del que a cambio se desprendería la pérdida de más de medio millón de puestos de trabajo en Estados Unidos hasta el año 2.000 (11). Este testimonio contradecía los resultados de un informe presentado en el Congreso en junio de 1991 por el Departamento de Estado en el que se estimaba que el 15 por ciento de cualquier crecimiento en los ingresos mexicanos serían gastados en bienes procedentes de Estados Unidos. Cada billón de dólares extra de exportaciones norteamericanas significaría que aproximadamente 22.000 nuevos puestos de trabajo serían creados en el mercado interno.

En octubre, Lloyd Bentsen, presidente del Comité de Finanzas del Senado solicitó a la Comisión de Comercio Internacional de Estados Unidos desarrollar un informe sobre las políticas comerciales de los países latinoamericanos y sus implicaciones para el futuro comercio norteamericano. Debido a que el Presidente había indicado su intención de negociar con Chile después de concluir el tratado con México, Bentsen demandó a la Comisión de Comercio Internacional prestar atención particular a ese país. Las consultas fueron mantenidas en enero, pero coherentemente con la historia completa de la Iniciativa para las Américas, causó más interés en América Latina que en

(9) Declaración del embajador Julius Katz ante el Comité de finanzas del Senado el 24 de abril de 1991. La misma actitud fue expresada por Myles Frecchette, Secretario del Representante de comercio de Estados Unidos para América Latina, el Caribe y Africa, en un discurso en la American University, el 12 de junio de 1991.

(10) Testimonio ante el "Trade Policy Staff Committee", Atlanta, GA, 29 de agosto de 1991.

(11) Samuel Bowles, et al, "Estimates of the Impact of the Free Trade Agreement on Direct U.S. Investment in Mexico", Estudio presentado al "Trade Policy Staff Committee Public Hearings", Boston, Massachussets, 11 de septiembre de 1991. 


\section{Estados Unidos.}

A medida que avanzaba el año y los temores públicos a la recesión se incrementaron, el argumento de los empleos perdidos pasó a un primer plano de una forma destacada. La oposición a la reelección del Presidente Bush emergió de entre las propias filas del Partido Republicano en la persona de Patrick Buchanan, que influyó directamente en el fracaso del Presidente, para pasar a prestar mayor atención a los problemas internos del país. El mismo argumento fue utilizado por Harrison Wofford en su triunfal campaña para Senador de Pennsylvania contra Richard Thornburgh, que contaba con el apoyo total del Presidente. Tras la campaña, Wofford creyó necesario distanciarse de Buchanan publicando un artículo en el Washington Post afirmando que él no era aislacionista (12).

La prensa en general se ocupó de la cuestión del proteccionismo, como una reflexión sobre el impacto de Buchanan en la campaña (13). El temor a que la pérdida de puestos de trabajo pudiera convertirse en tema clave durante las negociaciones con México, llevó al Presidente a sugerir al Presidente Salinas en la reunión mantenida en Camp David el 14 de diciembre, que podía ser necesario para México hacer concesiones complementarias en las negociaciones. Al mismo tiempo, la administración asumió un perfil público más bajo en las conversaciones y evitó toda mención a la posibilidad de comenzar a negociar con Chile en un futuro próximo. El Presidente mencionó el libre comercio en términos generales en un discurso pronunciado en su Estado en el mes de enero y relanzó la Iniciativa para las Américas en febrero.

Una vez que la amenaza que suponía Buchanan fuera superada hacia el mes de marzo, el Presidente se mostró más agresivo y expreso su disgusto por no poder llevar a cabo el tratado con México antes de las elecciones. En abril dijo ante el Consejo de las Américas que no dejaría que la campaña interfiriera en sus planes de firmar con México un tratado de libre comercio (14). Sin embargo, al mismo tiempo, los círculos oficiales en los departamentos de Estado y Comercio dijeron en privado que no había manera de que el borrador del tratado estuviera preparado antes de finalizar el año. Cuando se insistía públicamente en el momento en que las conversaciones podrían estar concluídas, la Representante de Comercio Carla Hills indicó que las fechas no eran importantes. Lo que sí era importante, añadió, era llegar a la consecución de un buen acuerdo que fuera apoyado de forma entusiasta por un ancho segmento del pueblo americano (15). Miembros del Congreso dudaron de que pudiera ser presentado antes de marzo de 1993. De hecho, más personal del Congreso, perteneciente a ambos partidos, estaba convencido de que el tema de los empleos era tan delicado que la administración haría apro- bar el tratado en el Congreso sólo a partir de un esfuerzo especial del Presidente en insistir en los intereses geopolíticos a largo plazo del tratado e hiciera menos hincapié en los económicos a corto plazo. Mirando más allá del Tratado de Libre Comercio y atendiendo la Iniciativa para las Américas, existe un peligro real, que la burocracia norteamericana no lo tratará con la suficiente rapidez. La autorización del "fast track" expira en junio de 1993. El ejecutivo debe concluir las negociaciones con México para entonces o el libre comercio latinoamericano puede colapsarse.

Los mexicanos se hallaban molestos por sufrir las consecuencias de la política interna de Estados Unidos. A continuación del encuentro de Camp David, en diciembre, los mexicanos filtraron a la prensa asuntos de especial relevancia que les atañían (16). En marzo, el Presidente Salinas pronunció un importante discurso en el que indicaba cómo podía reaccionar México ante el fracaso de establecer un Tratado de Libre Comercio y cómo su gobierno tomaría el rumbo de la "Democracia social" en lugar de la política de libre mercado que había sido desarrollada durante los tres años anteriores (17).

El tema del medio ambiente es uno de los que causa mayor tensión en las conversaciones entre América Latina y Estados Unidos. Un discurso reciente del embajador Rubens Ricupero sugiere que ésta constituirá la manzana de discordia fundamental en las negociaciones entre Estados Unidos y los países de la futura zona de libre comercio (18). Los latinoamericanos están preocupados por el uso que Estados Unidos haga del medio ambiente como arma en sus negociaciones sobre comercio. En efecto hay evidencias de que grupos ecologistas están preparados para hacer suyo ese cometido. De nuevo, sin embargo, es importante señalar que estos grupos ya han planteado el espectro de injustas desigualdades sobre las regulaciones medioambientales en las discusiones públicas de las negociaciones del GATT y desmentirían enérgicamente que ellos estuvieran discriminando a los latinoamericanos al incluir estas inquietudes en el debate sobre el Tratado del Libre Comercio y la Iniciativa para las Américas. Lo cierto es que los europeos se hallan bastante próximos a Estados Unidos en sus políticas medioambientales e incluso van por delante de los norteamericanos en algunas cuestiones. Ciertamente ese no es el caso de América Latina y el medio ambiente se constituiría en arma contundente utilizada contra los latinoamericanos en cualquier conversación en la que las regulaciones medioambientales fueran una condición de provecho para el libre mercado.

Hasta aquí, los resultados de la Iniciativa Bush para las Américas han sido mínimos. En sí misma, ésta no ha logrado prácticamente nada. Ha habido pocos beneficios directos

\footnotetext{
(12) Harris Wofford, "I'm No Isolationist", The Washington Post, 26 de diciembre de 1991

(13) Ver, por ejemplo, "Free Trade Politics", Christain Science Monitor, 23 de diciembre de 1991

(14) New York Times, 24 de abril de 1992.

(15) Sesión informativa de Carla Hills, Representante de Comercio de Estados Unidos, La Casa Blanca, 13 de diciembre de 1991

(16) "Mexico Worries U.S. May Stall Trade Pact", Los Angeles Times, 12 de diciembre de 1991

(17) Discurso del Presidente Salinas, 23 de marzo de 1991.

(18) Discurso pronunciado ante Trans Atlantic Futures, Washington D.C., 23 de febrero de 1992
} 
o a corto plazo. Un problema más serio, como Peter Hakim ha señalado, aduciendo un estudio del Banco Mundial, ha venido derivado de la excesiva propaganda que la Iniciativa ha recibido en América Latina (19). Incluso si todas las barreras al comercio con Estados Unidos fueran eliminadas, las exportaciones latinoamericanas a este último país sólo se incrementarían en un 8 por ciento. Este porcentaje no será suficiente para resolver los infortunios económicos de América Latina ni para animar el crecimiento por mucho tiempo. Así, el éxito de los modelos exportadores puede confirmarse efímero.

Sin embargo, los beneficios indirectos han sido significativos. Al menos, en el peor de los casos, la posibilidad de un área de libre comercio en el continente protegería a los países latinoamericanos frente a un resurgimiento del proteccionismo de Estados Unidos, aunque la eliminación de las barreras arancelarias ha llegado a ser tan compleja y la asimetría entre la economía norteamericana y las de los países latinoamericanos tan vasta que el libre comercio real se hallaría a muchas décadas de distancia bajo laš más favorables circunstancias, y, desgraciadamente muy retrasado en circunstancias más adversas. Aún ha habido importantes beneficios indirectos derivados de la Iniciativa para las Américas, incluso si tomamos el cruel o cínico punto de vista de su cumplimiento a corto plazo. Ha habido un incremento palpable en la confianza inversora en América Latina, como queda demostrado por la impresionante demanda de valores o títulos en un creciente número de intercambios en la región, y se ha producido una significativa afluencia de capital privado, al menos en algunos países, principalmente Chile y México. Si la Iniciativa para las Américas proporciona un refuerzo a políticas que son históricamente anómalas, políticamente vulnerables y propensas al ataque interno, todo ello puede hablarnos de la citada como una profecía autorrealizadora de la clase más positiva, haciendo las economías de los países latinoamericanos más competitivas en el mercado internacional.

Por añadidura, la Iniciativa para las Américas ha supuesto un poderoso estímulo a los esfuerzos de integración interregional mayores que en cualquier otro momento de la historia. En efecto, aun cuando la administración Bush fracase a la hora de percibir su parte de responsabilidad en la Iniciativa, si proyectos tales como MERCOSUR y el Pacto Andino son realizados y puestos en práctica, todos ellos reforzarán las economías de América Latina en un momento crítico de su desenvolvimiento y demostrarán ser un soporte poderoso para el fortalecimiento de la propia autoestima de los pueblos del continente. Irónicamente, Estados Unidos a fuerza de presionar a los países latinoamericanos para reestructurar sus economías, y ejercer un liderazgo sobre ellos fundamentado en una prometedora Iniciativa para las Américas anunciada de forma espectacular y luego frustrada por la incapacidad burocrática norteamericana, puede acabar reforzando el regionalismo latinoamericano (20). Históricamente, Estados Unidos ha preferido tratar con los países latinoamericanos uno a uno de forma individual, a la vez que se ha alejado de alentar esfuerzos combinados o multilaterales. Hoy, en las condiciones resultantes de la guerra fría, Estados Unidos necesita a América Latina para tomar parte en la liquidación de las disputas continentales, de la misma forma que europeas u otros aliados precisan de colaboración mutua para tratar con las crisis de Yugoslavia, Camboya, Irak o cualquier otro escenario, sea a través de las Naciones Unidas o de otras formas de esfuerzo colectivo. En el Hemisferio Occidental, Estados Unidos necesita el apoyo de aliados para hacer frente a las crisis de Haití o Perú. Precisa de aliados para ocuparse de modo efectivo del tráfico de drogas, o hacer frente a las amenazas al medioambiente. Esa necesidad de aliados, de compañeros como George Bush expresa, puede generar algunos cambios en la política norteamericana que no fueran enteramente previstos y que se opongan a la necesidad histórica de Estados Unidos de ejercer una política de mano libre en la acción continental.

¿Qué podemos esperar de la Iniciativa Bush para las Américas en Estados Unidos durante los próximos meses? Es cierto que en la práctica la administración Bush continuará apoyando la Iniciativa dado que encaja perfectamente en su política global. La Iniciativa es del todo coherente con la política de la administración hacia el GATT y su predisposición al libre mercado. La Iniciativa tiene la virtud de apoyar los esfuerzos norteamericanos de una comunidad global e incluso también mantiene abierta la posibilidad de consolidar a Estados Unidos como el líder de un bloque continental que debería convertir en necesaria semejante coalición estratégica en los años venideros. Tal estrategia es sugerida por aquellos que anticipan que la Ronda Uruguaya fracasará y que la economía mundial caminará hacia un incremento de la competitividad entre tres bloques: la Comunidad Europea, Japón y su periferia asiática, y Estados Unidos y América Latina (21). En el lenguaje de la teoría de juegos, la Iniciativa para las Américas genera una situación en la que todos los que participan en el juego ganan. Además, en tal situación, América Latina no tiene dónde ir, desde que sus socios comerciales europeos y asiáticos han venido a hallarse crecientemente preocupados con el comercio entre bloques y menos interesados en el bienestar de sus socios comerciales latinoamericanos. Finalmente, bajo cualquier escenario futuro del comercio mundial, la Iniciativa para las Américas es un elemento positivo puesto que estimulará las economías de América Latina, hecho que intensificaría la estabilidad política de los países de la región, inquietud permanente en Washington, a la vez que ayudaría a sus gobiernos a satisfacer las demandas de sus poblaciones mientras se convierten en mercados más atractivos para Estados Unidos.

En el frente interno de Estados Unidos, la Iniciativa para las Américas está inexplicablemente unida a las negociaciones con México del Tratado del Libre Comercio. Nada ocurrirá de momento hasta que esas conversaciones hayan

(19) Peter Hakim, "The Enterprise for the Americas Initiative", The Washington Quarterly, vol.15, num.2 (primavera, 1992).

(20) S. Weintraub, loc. cit.

(21) Lester Thurow, Head to Head. The Coming Economic Battle Among Japan, Europe, and America (NY William Morrow and Company, 1992). 
concluído. La suerte de estas vendrá determinada por la evolución de la recesión en la que Estados Unidos está inmerso y la conclusión de la Ronda Uruguay. Si las conversaciones del GATT sufrieran un parón, la administración redoblaría sus esfuerzos para concluir el Tratado de Libre Comercio. Si la recesión remite, será más fácil que el tratado sea aprobado por el Congreso. No obstante, aun cuando la recesión persista, el Presidente probablemente disponga de los votos necesarios para hacer aprobar el tratado en el Congreso; pero debe comprometerse públicamente con energía en conseguir su objetivo. A partir del verano de 1991, el Presidente Bush tuvo que preocuparse por su reelección y por la antigua Unión Soviética, a la vez que mantuvo un perfil bajo en el tratado con México, excepto en momentos determinados en que tuvo que hacer uso de la retórica. Estas cuestiones, junto con la profunda incomodidad del Presidente por tener que tratar con el Congreso y las diferencias reales complicando las conversaciones con México, son los peligros que pueden bloquear el Tratado de Libre Comercio. Si el tratado con México fracasa, la Iniciativa para las Américas quedará vacía de contenido. $\mathrm{Si}$ el tratado con México sigue adelante, las cuestiones a considerar se convertirán en: qué país de América Latina será el próximo en la misma línea para negociar un tratado de libre comercio; cuántos de dichos tratados puede negociar Estados Unidos; y, qué impacto tendrán los tratados en el comercio continental.

\section{RESUMEN}

El autor de este artículo aborda el análisis de la Iniciativa Bush para las Américas a dos años vista de su exposición por los portavoces de la Casa Blanca. Los escasos logros alcanzados no serán obstáculo para que Joseph S. Tulchin muestre un moderado optimismo por el desarrollo de la Iniciativa y los desafíos que le aguardan en los años próximos. Tras contextualizarla en el marco histórico del final de la guerra fría y del comienzo del desenvolvimiento a nivel global de las políticas económicas neoliberales, se pasa revista a los problemas por los que ha pasado la idea original en el interior de Estados Unidos y el entusiasmo con que fue acogida en América Latina. En este contexto uno de los primeros "tests" que pondrán a prueba el avance real de la Iniciativa para las Américas, será, sin lugar a dudas, la firma del Tratado de Libre Comercio (NAFTA) con México.

\section{ABSTRACT}

The author of this article tackles the analysis of the Enterprise for the Americas Initiative (EAI) two years after the White House spokesmen threw the idea. Scarce results achieved, won't be obstacle for Joseph S. Tulchin when he proves a moderate optimism with the development of the EAI and the coming challenges in the years ahead. After pointing the context out the EAI in the end of the Cold War and the evolution of neoliberal economics policies frame, he reviews difficulties to implement the original idea inside the United States and the enthusiastic reaction in Latin America. In this context, one of the first facts that will put the EAI real advance to the test, shall be without no doubt, the Free Trade Treaty(NAFTA) signing with Mexico.

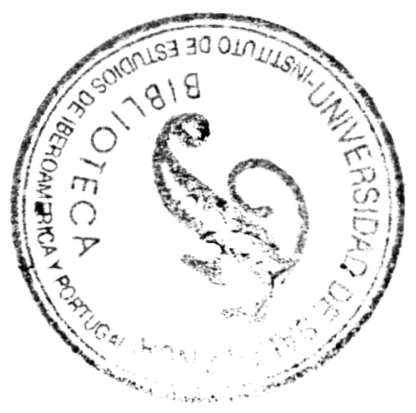

